\title{
Automatic Generation Of Geographical Information System (GIS) Dataset From Total Station
}

\author{
Mohd Amry Johan Mohd Ali, Jasmee Jaafar, Azman Ali M. Habib Rahman, and Warishah Abdul \\ Wahab
}

\begin{abstract}
A study towards optimizing engineering survey datasets towards Geographical Information System (GIS) data format is carried out. In this study, one hundred and thirty one (131) questionnaires were gathered from the licensed land surveyors in Malaysia who are the major contributors in carrying out engineering surveying work. It is found that, the data captured during field survey are in various formats and is not capable for direct usage in GIS environment. If the datasets are to be used in a GIS environment, further processing which involves expertise and manual editing need to be carried out as to comply with the GIS standard MS 1759:2004 data format. In this study, the automated system acquires engineering survey datasets from raw data generated by a variety of survey instrument and produce it to GIS ready format. The developed system is assessed qualitatively and quantitatively based on seven hundred and eighty eight (788) surveyed points. It is found that, in the qualitative approached; a good match is obtained in the plotted dataset. As for the quantitative approach, the accuracy achieved is less than 0.015 meters based on plotting points using AutoCAD and ArcGIS software. The results will be portrayed and tabulated accordingly.
\end{abstract}

Index Terms-Engineering survey, land survey, geographical information system, GIS, licensed land surveyor.

\section{INTRODUCTION}

In 2013, there are four hundred and thirty six (436) licensed land surveyors company established in Peninsular Malaysia [1]. All licensed land surveyors carried out their survey work using total station as a basic instrument for gathering site information. A diversity of surveying software is currently being used by the licensed land surveyors, to process their gathered datasets. Fig. 1 shows the data processing software used by various licensed land surveyors based on the questionnaire.

Referring to Fig. 1, it is shown that $83.5 \%$ of the respondents are using the product from Foresight Software Pty. Ltd. [2] known as CDS or Topographic Route and Processing Software (TRPS). Foresight Software Pty. Ltd. enters the Malaysia market and established a local distributor and a software called TRPS [2].

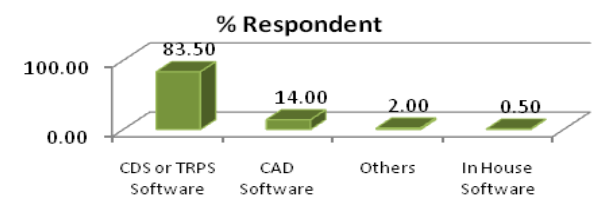

Fig. 1. Data processing method by licensed land surveyor.

Manuscript received March 18, 2015; revised May 10, 2015.

The authors are with Universiti Teknologi MARA, Malaysia (e-mail: amry.surveyor@gmail.com).
Where else, another 14\% equipped with Computer Aided Design (CAD) as a processing method in their practice, $2 \%$ utilized other software and $0.5 \%$ using in house customized software.

\section{Current Technique}

The majority of the licensed land surveyors in Malaysia is using CDS as their processing tools (Fig. 1). CDS is an integrated Windows based program designed for Surveyors, Engineers and related professionals [3].

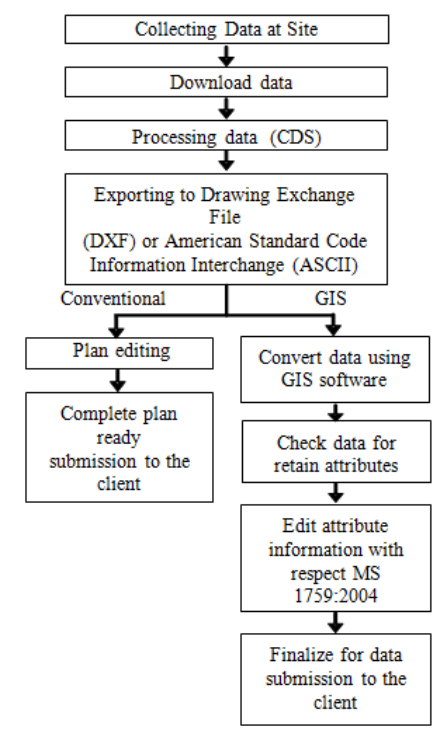

Fig. 2. Land survey work flow in producing GIS data format.

The current techniques of processing engineering survey data involve experts and it takes a long process which includes editing the dataset manually in order to comply with the GIS data standard. The process is time consuming, labor intensive and costly. Fig. 2 shows the general work flow in preparing the GIS final product.

Referring to Fig. 2, it is shown that various steps need to be carried out before the final GIS data format could be delivered. The process starts with data collection in the field using a total station. Upon completion the ground survey, the data is downloaded from the total station (survey instrument) using a downloader module dedicated to the total station (survey instrument) in used. The downloaded data will then be processed using CDS and exported to Drawing Exchange Format (DXF) or American Standard Code Information Interchange (ASCII).

In order to produce the GIS enable data format, a long process is needed [4], these include converting the dataset in 
readable GIS format, verifying and editing the attributes and finalizing process which involves overall checking.

\section{GIS DATASET}

Nowadays, Geographic Information System (GIS) is widely used in a diversity of applications [5]. It should be noted that, the main aim of engineering survey work is to produce an engineering plan. Hence, the data captured in the field by various land surveyors comprise of a variety data formats which relates to the software and instruments in used. The datasets are not for direct GIS usage. Based on the study, it is found that, licensed land surveyors in Malaysia are keen to have the surveyed engineering dataset in GIS ready format as it is highly demanded.

Fig. 3 shows the percentage of the licensed land surveyor demanding further study to be carried out to utilize the engineering surveyed dataset gathered towards GIS applications. Based on Fig. 3, it is shown that $75.38 \%$ strongly agree, $19.23 \%$ respond with no comment and only $3.85 \%$ does not agree, where else $1.54 \%$ had not responded towards utilizing the gathered engineering survey dataset for GIS applications.

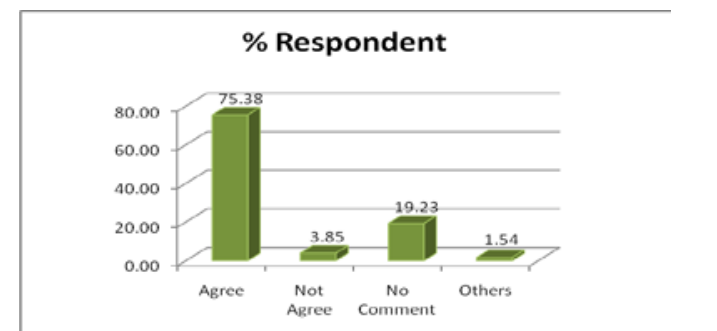

Fig. 3. Respondent by licensed land surveyors towards utilizing the engineering survey dataset for GIS usage.

\section{AUTOMATION TOWARDS GIS READY FORMAT}

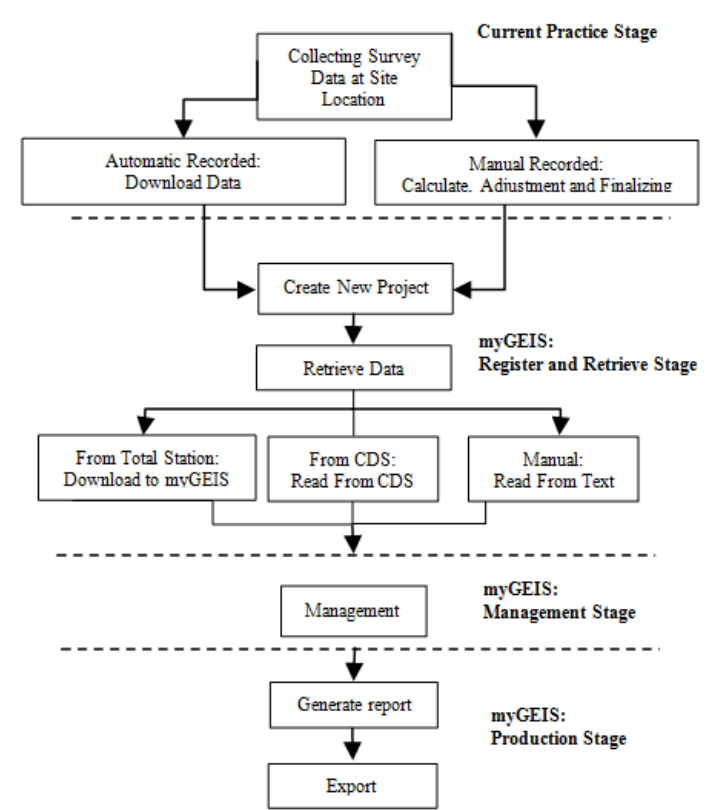

Fig. 4. Workflow of myGEIS system.

The automation module developed in this study is known as Malaysian Geographic and Engineering Information
System (myGEIS). With the capabilities design to automate many processes towards generating GIS Standard dataset according to the MS 1759:2004 the Geographic Information or Geomatics - Features and Attribute Code. myGEIS retrieve, process and convert land survey raw data consisting of surveyed information automatically. Fig. 4, shows the workflow of myGEIS system.

Referring to the Fig. 4, the workflow consists of four (4) stages, namely the Current Practice Stage, myGEIS: Register and Retrieve, myGEIS: Management and myGEIS: Production. On completing the current practice stage (field work), which eventually involves the normal ground survey data acquisition stage, the automation system is ready to be used.

Fig. 5 shows the main menu of the myGEIS system.

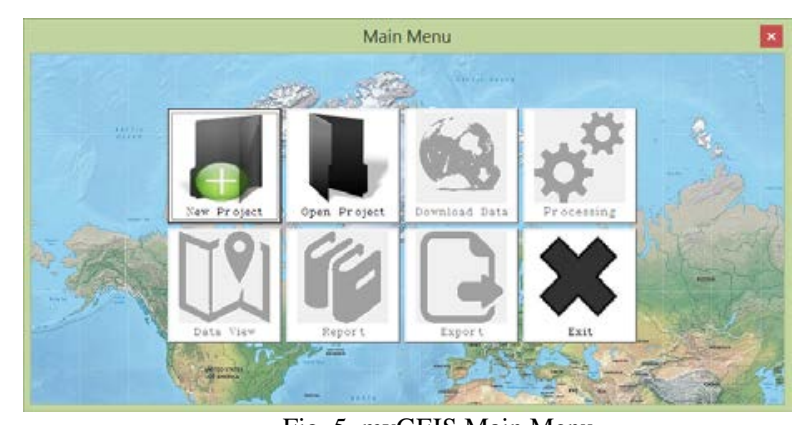

The system is also equipped with the management module which includes automatic survey correction, adjustment, and enables the user to perform editing and deleting of unwanted data. The Production Stage will then compile a report which includes the capability of exporting the dataset to MS 1759:2004 GIS formats. In this study, the developed system is assessed quantitatively based on seven hundred and eighty eight (788) surveyed points. It was found that, the accuracy (RMSE) achieved is less than 0.015 meters and portray a good match between the plotted dataset as shown in Fig. 6 . The test is based on the plots derived using AutoCAD [6] system and the generated GIS data plotted using ArcGIS [7] software.

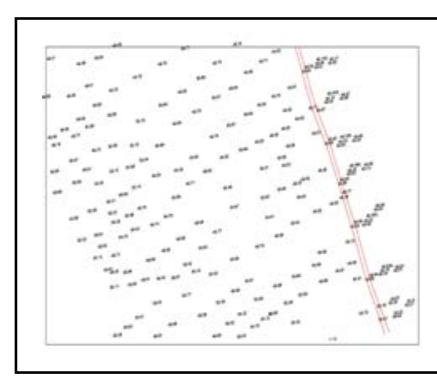

(a)

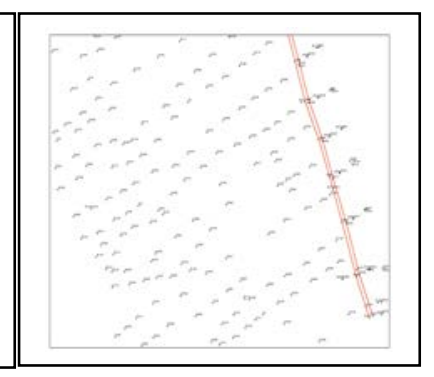

(b)
Fig. 6. (a) Data from Conventional Method and (b) Data Derived from myGEIS.

Referring to Fig. 6 (a), the data plotted is done by AutoCAD software derived from the conventional method while Fig. 6 (b) is generated using myGEIS system dataset plotted using the ArcGIS software. Both methods seem to give the same plot, but an additional benefit goes to the data generated by myGEIS where the attribute table will be 
automatically generated. This is of high advantage where it complies with the GIS standard MS 1759:2004 (Fig. 7).

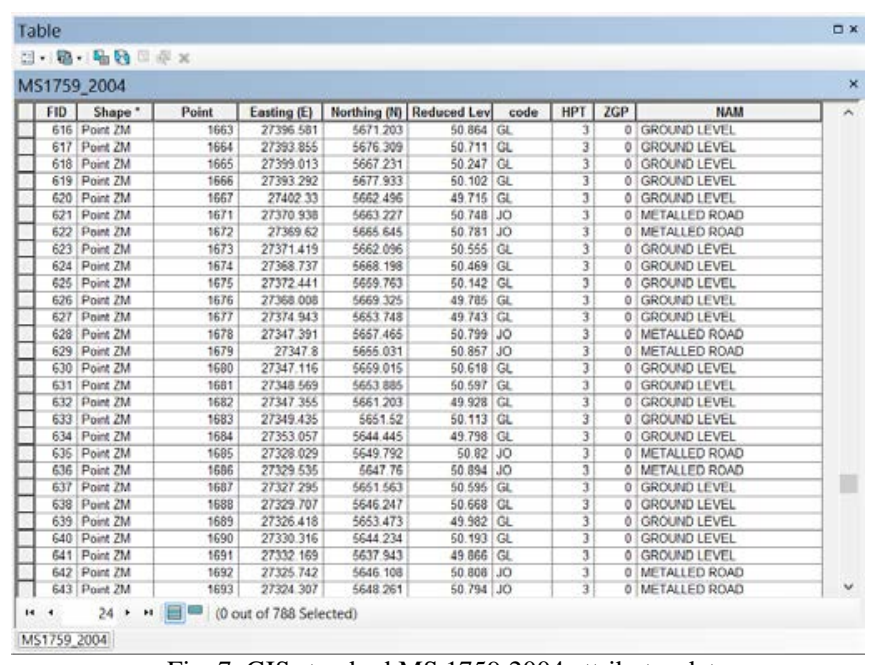

Fig. 7. GIS standard MS 1759:2004 attributes data.

Apart from the attribute table generated using the automated system developed, the time taken to generate the GIS ready data format is much faster compared to the conventional approached. In this study, seven hundred and eighty eight (788) point data is used for the evaluation process. Table I shows the recorded time to process the survey data using both semi-automatic (Conventional) and myGEIS method.

Referring to Table I, semi-automatic (conventional) method takes two thousand three hundred and fifty seven (2357) seconds to complete the process in preparing the GIS MS 1759:2004 ready data format. As for the myGEIS system, three hundred and fifty seven (357) seconds are needed to complete the whole process. It is shown that, the time taken is much shorter compared to the conventional method. It should be noted that, if the number of points to be processed increases, the time taken to process using the conventional method will eventually increase. Furthermore, as shown in Table I, the developed system does not require performing step 2, 3 and 4 towards the creation of GIS ready data format compared to the conventional method and this will save time and avoid human error.

Thirty (30) points were chosen randomly to distinguish if there is any differences in coordinate and reduced level value result of the processing and transforming to GIS data format. Table II shows the selected GIS data derived from myGEIS system. The data are retrieved from total station (instrument) and process automatically to GIS standard data.

TABLE I: TIME RECORDED TO PROCESS DATASET

\begin{tabular}{|c|c|c|c|}
\hline No & Step & $\begin{array}{c}\text { Semi-automatic } \\
\text { (Second) }\end{array}$ & $\begin{array}{c}\text { myGEIS } \\
\text { (Second) }\end{array}$ \\
\hline 1 & Data Download & 226 & 224 \\
\hline 2 & Data Cleaning & 120 & - \\
\hline 3 & $\begin{array}{c}\text { Create Comma } \\
\text { delimited text }\end{array}$ & 191 & - \\
\hline 4 & Export Shapefile & 177 & 129 \\
\hline 5 & $\begin{array}{c}\text { Editing and Create } \\
\text { GIS MS 1759:2004 }\end{array}$ & 1621 & 4 \\
\hline 6 & $\begin{array}{c}\text { Finalize GIS MS } \\
\text { 1759:2004 Data }\end{array}$ & 22 & 357 \\
\hline
\end{tabular}

TABLE II: SELECTED DATA FROM MYGEIS SYSTEM

\begin{tabular}{|c|c|c|c|c|}
\hline No. & $\begin{array}{c}\text { Point } \\
\text { Number }\end{array}$ & Easting (X) & Northing (Y) & $\begin{array}{c}\text { Reduced } \\
\text { Level } \\
\end{array}$ \\
\hline 1 & 112 & 987.22 & 973.756 & 99.441 \\
\hline 2 & 116 & 1007.4 & 976.886 & 99.741 \\
\hline 3 & 123 & 989.367 & 1006.457 & 100.021 \\
\hline 4 & 306 & 987.844 & 930.297 & 98.206 \\
\hline 5 & 307 & 992.797 & 949.309 & 98.436 \\
\hline 6 & 315 & 938.694 & 944.794 & 97.686 \\
\hline 7 & 334 & 966.526 & 947.04 & 98.306 \\
\hline 8 & 337 & 1016.905 & 954.202 & 99.436 \\
\hline 9 & 403 & 930.62 & 972.172 & 98.054 \\
\hline 10 & 417 & 963.903 & 969.137 & 98.164 \\
\hline 11 & 423 & 944.886 & 986.993 & 100.284 \\
\hline 12 & 502 & 907.811 & 1025.202 & 96.186 \\
\hline 13 & 503 & 921.757 & 1020.536 & 96.156 \\
\hline 14 & 513 & 949.38 & 1010.785 & 96.166 \\
\hline 15 & 516 & 886.711 & 1021.995 & 98.786 \\
\hline 16 & 526 & 909.647 & 1000.513 & 100.306 \\
\hline 17 & 7 & 911.395 & 1054.244 & 96.392 \\
\hline 18 & 602 & 888.257 & 975.763 & 98.362 \\
\hline 19 & 606 & 893.368 & 1046.868 & 98.912 \\
\hline 20 & 702 & 946.532 & 1096.075 & 100.715 \\
\hline 21 & 707 & 969.351 & 1051.311 & 96.915 \\
\hline 22 & 710 & 983.574 & 1023.282 & 99.485 \\
\hline 23 & 718 & 957.323 & 1037.111 & 96.225 \\
\hline 24 & 727 & 949.537 & 1062.89 & 96.165 \\
\hline 25 & 730 & 934.537 & 1069.558 & 96.245 \\
\hline 26 & 731 & 927.384 & 1052.738 & 96.165 \\
\hline 27 & 736 & 919.749 & 1094.578 & 101.555 \\
\hline 28 & 747 & 907.05 & 1076.218 & 101.335 \\
\hline 29 & 753 & 868.785 & 1022.928 & 100.525 \\
\hline 30 & 1 & 1000 & 1036.653 & 100.344 \\
\hline
\end{tabular}

TABLE III: SELECTED DATA FROM CONVENTIONAL METHOD

\begin{tabular}{|c|c|c|c|c|}
\hline No. & $\begin{array}{c}\text { Point } \\
\text { Number }\end{array}$ & Easting (X) & Northing (Y) & $\begin{array}{c}\text { Reduced } \\
\text { Level (RL) }\end{array}$ \\
\hline 1 & 112 & 987.219 & 973.757 & 99.441 \\
\hline 2 & 116 & 1007.399 & 976.885 & 99.741 \\
\hline 3 & 123 & 989.367 & 1006.458 & 100.021 \\
\hline 4 & 306 & 987.847 & 930.296 & 98.205 \\
\hline 5 & 307 & 992.797 & 949.308 & 98.435 \\
\hline 6 & 315 & 938.694 & 944.784 & 97.685 \\
\hline 7 & 334 & 966.527 & 947.036 & 98.305 \\
\hline 8 & 337 & 1016.904 & 954.205 & 99.435 \\
\hline 9 & 403 & 930.619 & 972.168 & 98.054 \\
\hline 10 & 417 & 963.903 & 969.137 & 98.164 \\
\hline 11 & 423 & 944.884 & 986.991 & 100.284 \\
\hline 12 & 502 & 907.805 & 1025.2 & 96.181 \\
\hline 13 & 503 & 921.752 & 1020.536 & 96.151 \\
\hline 14 & 513 & 949.376 & 1010.787 & 96.161 \\
\hline 15 & 516 & 886.705 & 1021.991 & 98.781 \\
\hline 16 & 526 & 909.644 & 1000.511 & 100.301 \\
\hline 17 & 7 & 911.387 & 1054.239 & 96.373 \\
\hline 18 & 602 & 888.253 & 975.762 & 98.358 \\
\hline 19 & 606 & 893.362 & 1046.867 & 98.908 \\
\hline 20 & 702 & 946.525 & 1096.073 & 100.699 \\
\hline 21 & 707 & 969.345 & 1051.31 & 96.899 \\
\hline 22 & 710 & 983.57 & 1023.281 & 99.469 \\
\hline 23 & 718 & 957.318 & 1037.109 & 96.209 \\
\hline 24 & 727 & 949.531 & 1062.888 & 96.149 \\
\hline 25 & 730 & 934.53 & 1069.556 & 96.229 \\
\hline 26 & 731 & 927.383 & 1052.736 & 96.149 \\
\hline 27 & 736 & 919.741 & 1094.575 & 101.539 \\
\hline 28 & 747 & 907.043 & 1076.215 & 101.319 \\
\hline 29 & 753 & 868.781 & 1022.923 & 100.509 \\
\hline 30 & 1 & 999.992 & 1036.648 & 100.339 \\
\hline
\end{tabular}


Table III shows the coordinate and reduced level from conventional method.

\begin{tabular}{|c|c|c|c|c|}
\hline No. & $\begin{array}{c}\text { Point } \\
\text { Number }\end{array}$ & $\Delta \mathrm{X}$ & $\Delta \mathrm{Y}$ & $\Delta \mathrm{RL}$ \\
\hline 1 & 112 & 0.001 & -0.001 & 0.000 \\
\hline 2 & 116 & 0.001 & 0.001 & 0.000 \\
\hline 3 & 123 & 0.000 & -0.001 & 0.000 \\
\hline 4 & 306 & -0.003 & 0.001 & 0.001 \\
\hline 5 & 307 & 0.000 & 0.001 & 0.001 \\
\hline 6 & 315 & 0.000 & 0.010 & 0.001 \\
\hline 7 & 334 & -0.001 & 0.004 & 0.001 \\
\hline 8 & 337 & 0.001 & -0.003 & 0.001 \\
\hline 9 & 403 & 0.001 & 0.004 & 0.000 \\
\hline 10 & 417 & 0.000 & 0.000 & 0.000 \\
\hline 11 & 423 & 0.002 & 0.002 & 0.000 \\
\hline 12 & 502 & 0.006 & 0.002 & 0.005 \\
\hline 13 & 503 & 0.005 & 0.000 & 0.005 \\
\hline 14 & 513 & 0.004 & -0.002 & 0.005 \\
\hline 15 & 516 & 0.006 & 0.004 & 0.005 \\
\hline 16 & 526 & 0.003 & 0.002 & 0.005 \\
\hline 17 & 7 & 0.008 & 0.005 & 0.019 \\
\hline 18 & 602 & 0.004 & 0.001 & 0.004 \\
\hline 19 & 606 & 0.006 & 0.001 & 0.004 \\
\hline 20 & 702 & 0.007 & 0.002 & 0.016 \\
\hline 21 & 707 & 0.006 & 0.001 & 0.016 \\
\hline 22 & 710 & 0.004 & 0.001 & 0.016 \\
\hline 23 & 718 & 0.005 & 0.002 & 0.016 \\
\hline 24 & 727 & 0.006 & 0.002 & 0.016 \\
\hline 25 & 730 & 0.007 & 0.002 & 0.016 \\
\hline 26 & 731 & 0.001 & 0.002 & 0.016 \\
\hline 27 & 736 & 0.008 & 0.003 & 0.016 \\
\hline 28 & 747 & 0.007 & 0.003 & 0.016 \\
\hline 29 & 753 & 0.004 & 0.005 & 0.016 \\
\hline 30 & 1 & 0.008 & 0.005 & 0.005 \\
\hline & RMSE & \multicolumn{2}{|c|}{0.006} & 0.010 \\
\hline
\end{tabular}

Assessment is measured using the Root Mean Square Error (RMSE) between data processed using myGEIS and derived value from conventional method. The RMSE calculation for $\mathrm{X}$ and $\mathrm{Y}$ (coordinate) value is based on (1) [8].

$$
\operatorname{RMSE}_{(x, y)}=\sqrt{\sum_{i=1}^{i=n}\left(\frac{\left(\mathrm{X}_{\mathrm{i}}-\mathrm{X}_{\mathrm{i}}^{*}\right)^{2}+\left(Y_{i}-Y_{i}^{*}\right)^{2}}{n}\right)}
$$

where

$n$ : is the number of points;

$X_{i}$ and $Y_{i}$ : is the coordinate produced by myGEIS system;

$X_{i}^{*}$ and $Y_{i}^{*}$ : is the coordinate of derived points from conventional method; and

\section{i : $1,2,3, \ldots \mathrm{n}$}

Meanwhile RMSE calculation for Reduced Level (height) value is based on (2) [8].

$$
\operatorname{RMSE}_{Z}=\sqrt{\sum_{i=1}^{i=n} \frac{\left(Z_{i}-Z_{i}^{*}\right)^{2}}{n}}
$$

where $n:$ is the number of points;

$Z_{i}$ : is the height of point generated using myGEIS;

$Z_{i}^{*}$ : is the height of point derived values from conventional method; and

i: $1,2,3, \ldots n$

Table IV shows the difference of coordinate and reduced level for the same point between the two datasets. The results of RMSE analysis done from the thirty (30) random point data in the study area. The RMSE is 0.006 Meter and 0.010 Meter is acceptable for the engineering survey job.

\section{CONCLUSION}

The Engineering survey work is highly demanded in land development activities of the nation. Licensed land surveyors are among the people responsible in gathering the ground survey data towards the preparation of topographic and other related engineering surveyed plan. It is also known that, high demand in GIS users emerged to support a diversity of applications. In this study, it is shown that the engineering survey data could be easily converted to GIS ready format using the developed automated system known as myGEIS to support GIS users. The main advantage of the automated system include, fast and accurate data conversion and eventually save cost.

\section{ACKNOWLEDGMENT}

The authors wish to thank the Centre for Geospatial Technology initiated by the Department of Surveying Science \& Geomatics, Faculty of Architecture, Planning and Surveying, Universiti Teknologi MARA, Malaysia, and the Institute of Graduate Studies (IGS), Universiti Teknologi MARA, Malaysia for supporting the research.

\section{REFERENCES}

[1] Lembaga Jurukur Tanah (LJT), Distributed Annual Diary, Lembaga Jurukur Tanah Malaysia (Land Surveyors Board) Kuala Lumpur, 2014.

[2] CDS, Corporate \& Product Overview, Foresoft Pty Ltd, NSW, Australia, 2012.

[3] CDS, CDS Calculation \& Design Software for Civil Engineers \& Surveyors, Foresoft Pty Ltd, NSW, Australia, 2005.

[4] J. Albrecht, "Key concepts and techniques in GIS: creating digital data," SAGE Research Methods, 2007.

[5] D. Yang, W. Zhang, and Q. Yao, "Geographic information system (GIS) is widely used in a diversity of applications," Trans Tech Publications, Switzerland, 2012

[6] Kempfer and Lisa, AutoCAD 2000, Computer - Aided Engineering, 1999, p. 20

[7] ESRI, What Is GIS? Environmental Systems Research Institute (ESRI) California, USA, 2012.

[8] J. B. Harley, The Accuracy of Ordnance Survey Maps, Ordnance Survey Maps a Descriptive Manual, The university press, Oxford, 1975.

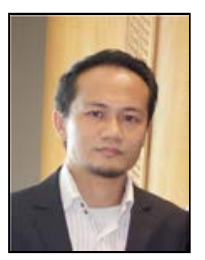

Mohd Amry Johan Mohd Ali was born in Kota Bharu, Malaysia on 29 July 1982. He received a bachelor of science in surveying and geomatics from UiTM Shah Alam, Malaysia in 2008. Now he is finishing a Master of Science degree in the built environment at the same university.

He is a land surveyor in a licensed land surveyor firm in Shah Alam, Malaysia and undergoing articleship.

Mr. Mohd Amry Johan Mohd Ali is a senior member of the Royal Institution Surveyor Malaysia (RISM) since 2010. 